\title{
The co-constitution of ageing and technology - a model and agenda
}

\author{
Alexander Peine ${ }^{1 \star}$ (iD) and Louis Neven ${ }^{2}$ \\ ${ }^{1}$ Copernicus Institute of Sustainable Development, Utrecht University, Utrecht, The Netherlands and \\ ${ }^{2}$ Avans University of Applied Sciences, Research Group Active Ageing, Breda, The Netherlands \\ ${ }^{*}$ Corresponding author. Email: a.peine@uu.nl
}

(Accepted 22 April 2020; first published online 3 June 2020)

\begin{abstract}
This paper presents a model for studying ageing and technology. It investigates the theoretical gains that can be made by combining insights from Age Studies and Science and Technology Studies (STS). Although technology has become a much more salient part in the everyday lives of older people and investments are high in technologies to deal with the alleged challenges of demographic change, theory development about ageing-technology relations has not kept up with these trends. Partly this is due to the poor connection between the social scientific understanding of ageing and the technically focused discipline of gerontechnology. This has led to an interventionist logic that underlies much of the current and implicit theorising about ageing and technology. We briefly analyse the problems of the interventionist logic and then present a model that conceptualises ageing and technology as co-constituted. We propose this model - which we call the CAT-model - to highlight a number of fundamental ideas about ageing-technology relations. At the centre are four different arenas (life-worlds of older people, design worlds, technological artefacts and images of ageing) in and across which these relations can and should be studied. To develop the model, we build on our own theoretical and empirical work over the last decade, and on examples from recent scholarship that straddle the disciplinary boundaries between STS and Age Studies.
\end{abstract}

Keywords: technology; older people; co-constitution; Science and Technology Studies; socio-gerontechnology

\section{Introduction}

Over the last decades, technology - digital technology in particular - has become a much more salient part of the everyday lives of most people. It is increasingly clear that older people are no exception to this. Indeed, technology plays a key role in the lives of older people (Higgs et al., 2009), including everyday devices like smartphones, fitness trackers or electric bicycles (Peine et al., 2017; Katz and Marshall, 2018; Fernández-Ardèvol et al., 2019). With the increasingly strong emphasis on ageing in place, which we can find in many Western societies (Van Hees et al., 
2018), also comes a focus on and a need for technologies specifically designed for older people - commonly referred to as gerontechnologies (Kwon, 2017) - like alarm pendants and passive monitoring (Aceros et al., 2015; Berridge, 2017). As a result, large-scale investments have been made into such 'gerontechnologies', which has led to a great diversity of prototypes, pilots and early stage businesses (Peine and Neven, 2011; Neven and Peine, 2017).

This increased importance of both the use of everyday technologies (see Hedman et al., 2018) in the lives of older people and the specific design and production of gerontechnologies has not been matched by a focus on improving the theoretical understanding of the relation between ageing and technology. In broad terms, following the work of French philosopher Bruno Latour (1993), the current situation is characterised by a 'Latourian divide' (Peine and Neven, 2019): on one side of the divide are the natural scientists, engineers and designers who are involved in the research, design and production of technologies. While they are involved - to various degrees - in researching and interacting with the potential end user, they are largely detached from the work that is going on at the other side of the divide. At this side, social scientists work on understanding the intricacies of the life-world of older people, the ageing process and how all of this is shaped by other phenomena. Technology, and the processes through which technology comes about, has not featured prominently on their agenda. While technology gains importance, the theoretical understanding of ageing-technology relations has been hampered by this Latourian divide.

In recent years a group of scholars has emerged that tries to straddle this divide. This group - for which the name Socio-gerontechnology is increasingly being used (Fernández-Ardèvol et al., 2019; Peine and Neven, 2019) - has engaged in rich empirical studies of various aspects of ageing-technology relations. They have studied both the design and the use of technologies - specifically designed for older people or everyday technologies used by older people. This has led to a flurry of conceptual results. While this group has tapped into an empirically and conceptually very rich vein of research, little attention has gone to developing overarching theoretical themes that help us understand the way ageing and technology mutually shape each other. In a world in which technology and ageing are increasingly becoming intertwined - both as the result of active innovation policy and as the result of the everyday actions of millions of individuals - there is a genuine need to improve the theoretical understanding of ageing-technology relations.

This article builds upon our conceptual and theoretical work over the past decade and sets out to develop a theoretical perspective that views ageing and technology as constituting each other. By this we mean that technologies for older people are partially shaped by ideas about ageing. For instance, whether older people are seen as active and competent or as sickly and technologically illiterate matters substantially for design decisions for a technology (Neven, 2010). Conversely, ageing is also shaped by technology. Ageing has, for instance, changed with the large-scale use of Facebook, Skype and WhatsApp by older people. Ageing and technology thus coconstitute each other. In what follows, we provide a model for understanding the co-constitution ${ }^{1}$ of ageing and technology (CAT) as a continuously evolving, cyclical relationship. We propose this model - which we call the CAT-model - to highlight a number of fundamental ideas about how ageing and technology are related, and we 
propose an agenda of how these relations can and should be studied. We first provide an overview of the core mechanics and features of our model. After this, we discuss four arenas in which CAT takes place and embed this discussion in examples from recent studies in the field of Socio-gerontechnology. Finally, we point out some larger ramifications of using the CAT-model as compared to other (implicit) models of ageing-technology relations which are currently used, such as those related to technology acceptance (see Peek et al., 2016) or various matrixes that single out the potential 'impact' of technology on certain aspects of later life (e.g. van Bronswijk et al., 2002; Sixsmith, 2013; Schulz et al., 2015). However, it is not our main intention to debunk any of these models in particular. In this article, we merely aim to point to some limitations in existing conceptualisations of ageing-technology relations that underlie such models, and offer ways forward to overcome such limitations productively. Also, our model does not make any ex-ante assumptions about specific kinds of technologies that would be especially relevant in relation to ageing. Rather, the model can be applied to understand how materiality - in general and including devices, software and infrastructures - matters and comes to matter for older people. Hence, we talk about technology in a broad sense throughout this article, and discuss specific technologies only as examples to illustrate conceptual claims that pertain to technology in general.

\section{The co-constitution of ageing and technology}

We have developed the notion of the Latourian divide in a recent article in which we critically explore the state of the art in theorising about ageing and technology (Peine and Neven, 2019). While others have pointed out before us that the vast literature on ageing and technology has remained largely atheoretical (Sixsmith, 2013; Schulz et al., 2015), we were looking for implicit theories about how ageing and technology are related. Building on the work of French philosopher Bruno Latour, we argued that the mainstream of work in gerontology and on gerontechnology makes a neat divide between the side of technology and engineering, which is focused on solving the 'problems' of ageing by technological means, and the side of the social analysis of older people in which technology is just a tool or instrument. Design, then, is the arena in which new technologies are explored, while knowledge about ageing or older people serves as a target. This is the arena that gerontechnologists explore but that has hardly received the attention of scholars working on ageing and later life (we turn to some of the exceptions below). The lives of older people, on the other hand, are the domain of Age Studies, ${ }^{2}$ but here little attention has been given to technologies or materiality as theoretically interesting factors in later life (we turn to some of the exceptions below). This has led to a situation that resembles Latour's (1993) classic analysis of modernity: social scientists attend to the social lives of older people to understand age and later life; engineers and designers attend to creating technology that suits the lives of older people, or that can positively intervene into certain aspects of it.

For our purpose, the Latourian divide is important because it has produced implicit, yet powerful theoretical assumptions about ageing-technology relations for which we have coined the term interventionist logic (Peine and Neven, 2019): the interventionist logic conceptualises ageing to be a target for technological 
design. Designers and engineers, often with the help of social scientists, attend to ageing as a target for interventions or as a set of problems to be solved. On the flip side, the interventionist logic conceptualises technology to be an instrument. Age Studies, as far as they have attended to technology at all, primarily study technology in terms of their impact on or their acceptability in the lives of older people (McCreadie and Tinker, 2005; Sixsmith, 2009; Schulz et al., 2015; ten Bruggencate et al., 2019). Older people are seen as needing technological interventions and an implicit but strong relation between ageing and care is drawn.

The interventionist logic and the implicit theoretical assumptions that it makes have produced potent prescriptions for how and where ageing-technology relations should be studied: there is a widespread and persistent idea that the worlds of designers and engineers produce material objects above all. It is often taken for granted that the design of such objects addresses specific aspects of ageing. Robotic pets like Paro are, for instance, designed to provide a companion and elicit an emotional response. Yet, while it would seem sensible to us to understand exactly how design worlds select and articulate such aspects alongside material objects, it is normally assumed that some form of user or expert involvement can provide an unfettered view on ageing. Design worlds are normally not considered to be sites that articulate versions of ageing together with the production of technology.

At the same time, it is still a persistent belief that technology only plays an ancillary and neutral role in the lives of older people. The life-worlds of older people are the sites where the changing experiences and practices of ageing are studied. Yet, while it becomes increasingly clear that technical objects populate the lives of older people, technology has not received much attention as an important factor in shaping ageing itself (Peine et al., 2015). In many social science studies, it is still the predominant view that it is the task of gerontology and Age Studies to understand motivations for the use or acceptance of technology (Peek et al., 2016), or evaluate the impact of technology along pre-defined dimensions (Schulz et al., 2015). Yet, while it would seem more sensible to us to study how older people themselves explore and define relations with technologies that are meaningful to them (cf. Gibson et al., 2019), it is usually assumed that what technology can do and mean for older people is an inherent and stable property of these technologies. The life-worlds of older people are usually not considered to be sites that define technologies together with changing experiences of ageing.

Under the Latourian divide, ageing-technology relations are carved up and as a result they are only partly understood. Careful readers will have recognised that our reference to a Latourian divide is a shorthand to point out the relevance of Science and Technology Studies (STS) to theorise about ageing and technology. Indeed, it is a conceptual weakness of the interventionist logic that it has expelled the very relations between ageing and technology to the margins of the theories in both gerontechnology and gerontology (Peine and Neven, 2019). The relations between people and technology are very prominent, empirically and theoretically, in STS. STS has shown how technology and people can only be understood in relation to each other; they inhabit the same worlds and bring each other into existence (Sismondo, 2010; Felt et al., 2017). Interventionist assumptions about human-technology then appear to be theoretically naïve and they become difficult to uphold. 
It is in this intellectual tradition that, next to what could be called 'mainstream' studies on ageing and technology, an increasing number of scholars (including ourselves) have started to explore the usefulness of bridging insights and concepts from STS and Age Studies. This is the emergent field of Socio-gerontechnology that we referred to in the Introduction. A persistent theme that emerges from these studies is what we have called the co-constitution of ageing and technology (Peine and Neven, 2019), or simply CAT. At the core of the notion is the argument that ageing and technology mutually constitute each other, and that CAT needs to be studied at different sites, including design worlds and life-worlds. Co-constitution refrains from an a priori analytical difference between these worlds: both are (diverse) social worlds in which ageing and technology come into existence together, and where we can thus study how they are constitutive for each other.

Theoretically, CAT relaxes implicit notions of stability inherent to the interventionist logic. Where design worlds usually assume that ageing (however nuanced it is understood) is a stable target for technology interventions, CAT implies that technology is constitutive for ageing itself. Hence, CAT avoids the assumption that the forms and practices of ageing pre-exist the technologies that are supposed to intervene in them. And where typical intervention studies would assume technologies to be stable (and thus comparable) across instances of their use (e.g. McCreadie and Tinker, 2005; Schulz et al., 2015), CAT assumes that ageing is constitutive for technology, too, when multiple versions of a technology come into existence across different instances of their appropriation and use. ${ }^{3}$

\section{The CAT-model}

In what follows, we elaborate the CAT-model that we propose as a basic framework for studying ageing-technology relations. As we do so, we also elaborate further upon the basic theoretical tenets of CAT and illustrate this with examples from empirical studies that have taken conceptual cues from both STS and Age Studies. These empirical studies are, in our view, exemplary to demonstrate the value of the CAT perspective. This does not imply that these studies necessarily share our view on CAT or the idea that we need a model to study CAT. Instead, we mean to propose our model to extract some basic features that transpire from recent empirical work that have, in our view, questioned the interventionist logic. With the CAT-model, we provide a basic conceptual standpoint which can be (creatively) connected to various concepts from STS and Age Studies.

In its most basic form (see Figure 1), the CAT-model identifies four distinct arenas in which CAT takes place and can be studied. These four arenas are arranged in a cyclical pattern. One can investigate one of these arenas or track the development and use of a technology through one, several or all of the arenas, and an analysis can start at any point. While we address some of the complexities of the arenas and the translations from one arena to the next below, it suffices at this point to highlight the basic mechanism of the model. ${ }^{4}$ This mechanism draws from work in STS that has pointed out that designs of any technology, technologies for older people being no exception, do not emerge out of nothing. Indeed, STS scholars like Madeleine Akrich or Bruno Latour (Akrich, 1992, 1995; Akrich and Latour, 1992) showed long ago that designers and engineers create imaginations 


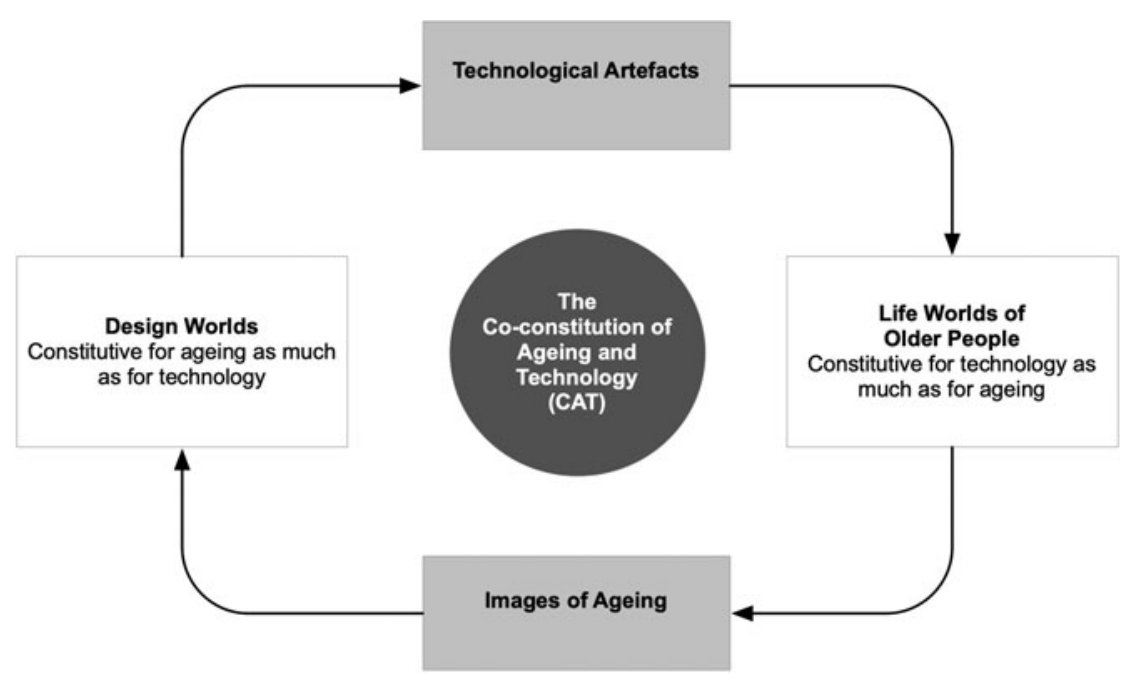

Figure 1. The basic structure of the CAT-model.

of the user, of the the life-world of the user and of how the innovation will figure in this life-world. The basis for such imaginations differs widely; they may be based on detailed ethnographical study, but also on nothing more than a vague (stereotypical) idea of what older people and their life-worlds are like (Peine et al., 2014).

Such images of ageing-or 'user representations' in STS language (Akrich, 1995) - form a basis on which to take decisions about the design of a technology in the design world. This is a world in which professionals, designers, engineers, craftsmen, managers, etc., work on designing and producing technologies. Typically, the context of this world is a business or research institute with its own restraints, challenges and opportunities (Mackay et al., 2000). Ultimately, a technology for older people is produced in this world. These technologies have certain scenarios for use - or 'scripts' in STS language (Akrich, 1992) - designed into them. These scripts may be unintentionally designed to enable and constrain the actions of an older user, but the enabling and constraining effects can also be very deliberate acts of the designers and engineers based on their ideas of what is a good, safe, appropriate, etc., behaviour of an older person. Technologies imbued with these scripts finally enter the life-world of older people. ${ }^{5}$ There they may indeed constrain and enable the actions of older people, but older people are not necessarily passive recipients of such technologies (Oudshoorn and Pinch, 2003a). They may adapt, circumvent, use selectively or decide not to use a technology at all. But the technology can be subsumed in the life-world of older people. Once there, it also starts to re-shape the forms and practices of ageing. Thus, in its most basic form, the CAT-model points to the fact that the design and use are reciprocally related. Both are worlds that should be studied if we want a full empirical understanding of what it means to age with technologies and how these technologies and indeed this ageing comes about. Images and technologies travel between these worlds and provide links between them. In the following four sections we discuss all four arenas and the way they are related in more detail. 


\section{Technology and the life-worlds of older people}

The life-worlds of older people are well understood in Age Studies. This knowledge is a necessary precondition in understanding the relation between the older person and the technological artefact as many aspects of the life-world may have an effect on this relation. The life-world contains the older person in his or her social and technological context. It may thus include friends, family, formal and informal carers, and others, but also a broad range of pre-existing low-tech and high-tech technologies and technological skills (Loe, 2010; Peine et al., 2014; Giaccardi et al., 2016; Rosales and Fernández-Ardèvol, 2016). The older person is obviously diverse. There may be differences in health, gender, race, social status, economic status, consumption patterns, personal preferences, personal history, creativity, interest in technology, technology generations, technological literacy, etc. All of these may have an effect on how a technology is or is not appropriated, how it is and is not used, how it is or is not modified, etc., and thus what role the technology comes to play in the life-world of an older person, thereby obviously altering the life-world again.

The life-worlds of older people are obviously sites where ageing is constituted, and they have been widely studied as such. The CAT-model highlights that lifeworlds are sites for the constitution of technology, too. That is, we do not assume as mainstream interventionist studies would do - that a technology, singular, has a well-defined and measurable impact on the lives of older people. Instead, the CAT perspective asks for and renders visible the many existences - which can be creative, limiting, meaningful, disappointing, and so forth - that a technology obtains in the worlds of older people and thus in relation to ageing. So, for instance, the interventionist logic would ask how the use of a smartphone increases or decreases the frequency and duration of communication with other humans as a measure of the impact of smartphones on the social connectedness of older people. By contrast, the CAT perspective asks how the ideas of the quality and meaning of communication change with the advent of a smartphone in the life-worlds of older people. This distinction is subtle but important: the former assumes social connectedness as something that is defined by human relations; the latter looks into relations between humans and smartphones, and asks how both social connectedness and smartphones are defined in these relations and in specific situations. The implications of this distinction for studying ageing-technology relations are immense, as the following examples show.

Berridge's (2016) work on passive monitoring systems and privacy demonstrates how categories like privacy are themselves re-negotiated in relation to new technology. She departs from a critique of mainstream approaches in ethics that would analyse how far monitoring devices impact upon privacy. Implicit to this view, she argues, is a static notion of privacy that can be used as a benchmark that exists independent of technology. Berridge (2016: 808) writes: 'Given the creative possibilities and achievements of technological innovation, this simplistic exchange theory is perplexing.' To counteract over-simplification, her work highlights multiple articulations of privacy that were created in the interactions between older residents, monitoring devices, family members, monitoring staff, and so forth. In this view, it becomes clear that the new monitoring device did not just impact on a static idea of 
privacy. Rather, multiple situated versions of privacy emerged that were constituted in specific interactions between older people, care-givers, home environments, monitoring devices, etc. As part of these interactions, the monitoring device also became different things. In some cases, it was an intruder to a life-world that was considered private, while in other cases it was an enabler of keeping one's private life despite feelings of vulnerability and unsafety (Berridge, 2016: 812). This throws into question the notion of the monitoring device as being stable, as the following example highlights more explicitly.

During the international EFORTT project, researchers have followed Telecare devices such as alarm pendants and sensor devices into the homes and lives of older people in four countries (Mort et al., 2015). The researchers refrained from assuming $a$ priori that there was just one version of a technology that was installed in different homes. Rather, they mapped how different installations produced different versions of the technology in question. For instance, López Gómez (2015) has shown how many of the alarm pendants he observed and that were meant to be constantly 'on' were only used in selected places and during selected periods of time. For the technology providers, these alarm pendants were unruly and noncompliant. They violated the rules of good behaviour that the installers had formulated for alarm pendants and were thus unable to realise the 'impact' that was foreseen for these pendants. For the older persons, however, these 'unruly' pendants were meaningful and functional exactly because they deviated from the prescriptions of good behaviour. These alarm pendants behaved well in relation to the many subtle arrangements that were already in place in their life-worlds. It thus became futile to talk about an alarm pendant. Rather, the worlds of older people and the worlds of technology constituted quite different alarm pendants - meaningful one world, and unruly in the other.

The STS sensitivity towards multiple existences of an object that informed these studies allowed the authors to explore the life-worlds of older people as relevant sites for the constitution of both ageing and technology. More precisely, they highlight how (aspects of) ageing and technology obtained specific identities only in relation to each other. Following such insights, the CAT-model invites us to study the life-worlds of older people free from pre-conceived notions of what the life-world, the technology and their relation is. Rather, the CAT perspective brings into sight the multiple networks and arrangements of relations that users and technologies negotiate during the installation and appropriation of new devices.

It is, of course, not a stranger to Age Studies that ageing is constituted in the lives of older people. The STS perspective adds that the same holds for technology: CAT does not assume that a technology has a fixed identity outside specific relations of their appropriation and use, and it neither assumes users to have such a fixed identity (Barad, 2007; Suopajärvi, 2015). ${ }^{6}$ At the very least, this is a basis to question simplistic and linear notions of impact, and complement them with empirically grounded understanding of how impact is an accomplishment. It also brings out how the very categories and values we use to measure impact or to assess acceptability are dynamic (for this point in general, see Kudina and Verbeek, 2019); they need to be traced as they are re-constituted in interaction with technology, rather than pre-supposed. The complicated interactions of technologies and older people are, however, to a degree also pre-shaped by the design - and the 'script' - of a 
technology. These designs and scripts do not emerge out of nothing. They rely on, and indeed translate, interpretations or images of older people. It is to these images that we turn next.

\section{Images of ageing}

Images of ageing are a key topic in Age Studies, which have long shown that the public imagery perpetuated in marketing practice, media, art or fashion contribute to the cultural matrix that shapes age and ageing (Featherstone and Wernick, 1995; Katz, 2001; Meagher, 2015; Marshall, 2018; Twigg, 2018). What is probably less well understood in Age Studies is that there is also a crucial link between the way ageing is imagined, by individuals but also in broader society, and the development of technologies for older people. ${ }^{7}$ Designers and engineers are actively involved in gathering information about and in creating an idea of the future user of their technology (Woolgar, 1991; Akrich, 1992), and there can be various sources for such ideas about future users and use. These sources can include public imageries, idiosyncratic personal accounts, organisation- or sector-specific design traditions, or more or less elaborate types of user involvement (Akrich, 1995; Oudshoorn and Pinch, 2003b; Hyysalo, 2009; Peine and Herrmann, 2012).

Technologies designed for older people are not an exception to this. In the CAT-model, we thus point to images of ageing as an integral and pivotal part of the development of technologies for older people. As such it is a fundamental area of enquiry for Age Studies and STS alike. Images of ageing deserve our attention as 'actors' that influence designs and the design world, and thus also the way in which technologies for older people are designed and marketed. Images of ageing link the life-worlds of older people and (societal) imaginaries about them with design worlds.

The CAT-model highlights the relations between the life-world of older people and the design world via images and simultaneously problematises this relationship. The images of ageing used in the design world can, but do not necessarily have to, stem from (studying) the life-world of older people. Indeed, societally or personally held stereotypical and sometimes outright ageist views of older people can also be fed into the loop at this point, often without designers, engineers or innovation policy makers being aware of such biases. Scholars at the intersection of STS and ageing have extensively mapped and critically questioned the often simplistic and negative ageing myths that inform design (Östlund, 2005; Joyce and Mamo, 2006; Neven, 2011; Peine and Neven, 2011; Vines et al., 2015; Cozza et al., 2017), and showed how they can be powerful influences on the work of designers.

For instance, Neven (2010) showed that designers themselves often hold powerful stereotypes about older people. He studied the ideas about older people that informed the design and test-use of a robot and showed how publicly shared negative images of ageing came to dominate over the more positive imagery put forward by older test users. While the test users made it very clear that they did not recognise themselves in images which emphasised frailty, dependence and decrepitude, their views were not taken seriously. In Neven's study, designers made choices about which responses of older test users they took seriously based on ageist 
stereotypes. These stereotypical images about older people thus provided a powerful practical guidance to these designers.

Innovation funding or policy programmes can be another important link through which images of ageing influence technology design. Broad societal discourses around ageing, such as demographic fears, the digital divide, anti-ageing or the alleged opportunities of the 'silver economy', influence how design projects are legitimised, funded and structured. For instance, Marshall and Katz (2016) have shown how the biopolitical discourse around new digital technologies (specifically fitness trackers and brain games) produce new normativities of 'quantified ageing'. They argue that 'technological developments, demographic shifts and changing regimes of governmentality conjoin to problematize ... ageing bodies' (Marshall and Katz, 2016: 150). Subsequently, such versions of ageing bodies and brains as 'measurable, manageable and optimizable' (Katz and Marshall, 2018: 67) are used to legitimise investments into particular kinds of digital innovation, such as fitness trackers (see also Urban, 2017). Similarly, Neven and Peine (2017) have analysed the rhetoric of European innovation and innovation funding policies in relation to demographic change. They identified a remarkably consistent discourse - which they term the 'ageing-and-innovation-discourse' - that has produced a predominantly negative imagery of older people as frail and needy, and limited funding to those technologies that can meaningfully relate to such frail and needy older people.

To sum up, both the 'grand narratives' and the individually held images, e.g. by designers, matter, and indeed the grand narratives often influence, implicitly or explicitly, the images of ageing used by designers and engineers (Neven and Peine, 2017). It is to how these individually held images of ageing and older people, and how they influence and are moulded in design worlds, that we turn to in more detail next.

\section{Ageing and design worlds}

As we have seen in the life-world of older people, ageing and technology are intimately intertwined. This is also the case for the corporate world in which technologies for older people are produced. The CAT-model highlights that the worlds of technology and innovation are constitutive for ageing as much as they are constitutive for technology. Ageing can and should be studied in these worlds, too. Laboratories, design studios, board rooms of technological corporations, innovation policy discourses, media representations of new devices, etc., are sites where ageing is produced as much as in stereotypical places like nursing homes or ocean cruise liners. Hitherto, attention for these design worlds has not been great in Age Studies (notable exceptions are Twigg, 2012; Buse et al., 2017). It has been in STS, but rarely with explicit attention to ageing (Joyce et al., 2017). Yet, we argue that we should be more interested in design worlds as sites where ageing is created in specific relation to emerging technologies. Such an attempt may profit from insights and approaches in STS, which has a long history of studying venues where scientific knowledge and technologies are produced (e.g. Latour and Woolgar, 1979; Latour, 1987). There is a broad conceptual, theoretical and methodological basis to draw from: the design world is, by and large, a world of 
professionals often with a background in design and engineering, but which may also include managers, psychologists, ethnographers, craftsmen and others. It is a creative world in which technological concepts and components are brought together with images and ideas about the needs and wants of a prospective nonexisting user (Bucciarelli, 1988; Woolgar, 1991).

While the design world is a creative world, it is not a boundless unconstrained world where anything and everything can be designed and made. In the context of a business or institute there are financial and temporal constraints. Indeed, it is important to realise that the design world is not necessarily focused on or committed to design for older people. Technologies designed for other audiences may be repurposed for older people or technological options that stem from basic research may 'find' an application in the design of technologies for older people. Moreover, there are also design methodologies, habits, laws, patents, and company and government policies which enable and constrain what designers and engineers can and cannot do (Mackay et al., 2000). In addition, design often also entails a need for reduction of complexity (Pollock et al., 2007): the rich insights that, for instance, ethnographers or other social scientists may contribute to projects has to be translated into design decisions. It is then a 'fallacy' to assume that more knowledge about potential users translates unfetteredly or even easily into design decisions (Stewart and Williams, 2005), let alone into 'better' designs. Specificities of the knowledge gained along the way needs to be 'designed out' (Oudshoorn et al., 2004) in order to devise a technology that is suitable for a broader audience and thus has broader (commercial) appeal. Such processes of 'generification' are important to understand how certain ideas about users become inscribed into designs, while others are sidelined or ignored (Pollock et al., 2007).

Scholars at the intersection of STS and Age Studies have started to explore this idea in the context of designing for older people. For instance, Peine and Moors (2015) have analysed two projects that designed social robots for older people. They elaborated upon the many ways in which designers articulated ageing at various stages in the design process. How come, they ask, that certain ideas about ageing became part of the design of the robot labs, while others did not? To answer this question, they highlighted the many ideas of ageing that the designers almost constantly created together with various design features. They found that both projects initially incorporated very broad and diverse ideas of ageing. However, as the projects proceeded, these ideas were limited to a much narrower set of ideas that were associated with frailty and impairment. The narrowing down was not the result of explicitly thinking about old people. It rather emerged as a practical by-product when decisions about specific requirements for the robots, and the manageability and scalability of the projects, had to be made. During such design decisions, those aspects of ageing were frequently prioritised which could easily be translated into specific and generalisable design requirements (e.g. forgetfulness was an easier priority for the robot projects than, say, lack of social connectedness), or aspects whose relevance could easily be quantified in terms of societal and economic costs (which is, for instance, easier in the case of falls prevention rather than social media access). Such 'parameterisation' created and prioritised deficit ideas of ageing, which were constituted in the many technical and practical demands and constraints of the projects, somtimes including 
policy priorities of funders, few of which had to do with ageing or older persons per $s e^{8}$

Another example of the reduction of complexity and the 'designing out' of multiplicity comes from Buse et al. (2017). With a background in Age Studies but engaging with the STS literature on 'multiplicity' (Mol, 2002), Buse et al. (2017: 1440) explored how architects of residential care homes anticipated the ageing bodies in 'the planning, construction and completion of buildings'. While these designers of care homes anticipated multiple ageing bodies in nuanced ways, they needed to compromise constantly on this multiplicity because of the practical constraints of the design processes. Most notably, existing ideologies of care as well as the collaborative nature of the design process constantly interfered with their imaginations of ageing bodies.

These studies show that design processes need to deal with 'excess' complexity and information about ageing and older people. Especially with elaborate forms of user involvement (Peine et al., 2014), designers have to deal with conflicting and ambiguous ideas about ageing and older people. To be sure, such conflicting ideas are reconciled during the practicalities of design. But this means that the ideas of older people that eventually emerge as prospective users are mediated and contingent. They can be based on the necessity to create 'doable problems' (Lassen et al., 2015).

Design worlds and the design practices within them are important arenas for the study of ageing. The interventionist logic would seem to imply that unmediated views on ageing and older people are possible and desirable, and will lead to more acceptable or 'better' designs. The studies discussed above show that this assumption is misleading because it ignores the tensions and contradictions that design worlds need to resolve. The complexity and diversity of the life-worlds of older people cannot be fully encompassed in a design. Invariably design also means making choices and even if a designer has intimate knowledge of the lifeworld of older people not everything can be taken into account. That said, overly simplified images and imagery that rely on societal stereotypes instead of proper research into the lives of older people are most definitely a very problematic basis for design decisions. While designers and engineers face constraints and are not omnipotent 'magicians of technology' who can create anything, this does not mean that they are relieved of the task of properly engaging with older people or at the very least reflecting critically on the images of ageing on which their designs are based.

The CAT-model can help with this task. It stresses that design produces ideas about ageing and older people as much as it produces technology. Such ideas can include ideas about ageing bodies, ideas about adequate role models, proper actions to be taken in relation to the technology, and so forth. It is an empirical question to understand the conditions under which such ideas come to prevail rather than others. As Buse et al. (2017: 1452) have pointed out for Age Studies, this 'suggest $[\mathrm{s}]$ the importance of turning the lens to the practices of designers more generally, as part of understanding how later life is "imagined, performed and experienced in contemporary culture” (Twigg 2012: 1049)'. From STS we get a more specific understanding about why and how such ideas of older people that are created, implicitly or explicitly, matter and why we need to take them seriously 
in our understanding of ageing. This brings us to the last element in our model where we discuss technological artefacts. We extend in more detail the argument that ideas of ageing are not only created in design, but also inscribed into objects. Through these objects they move back or travel into the life-worlds of older people, where they can have enabling or constraining effects.

\section{Technological artefacts}

Design worlds and life-worlds of older people are obviously linked. Above, we discussed the link via images of ageing and in this section, we discuss the more obvious and visible link: technological artefacts that travel from the design world to the lifeworlds of older people. Technologies are designed and manufactured in the design world, a world of corporations, start-ups, research institutes, etc., and they travel to the life-world of users. Older people periodically become new users of technologies that were made somewhere for some reason with some idea of (older) people in mind. The CAT-model emphasises that the versions of ageing created in design worlds matter in the life-worlds of older people through the technological artefacts that are transferred. Artefacts enter the lives of older people with norms and role expectations, and technologies may enable, but also constrain certain actions. One of the key points is that the norms, roles and ideas about 'proper' actions to be or not to be undertaken by an older person are literally built into the technology, or 'inscribed' in STS terms. Decisions made by designers about norms, roles and proper conduct are thus materialised and, at the same, it may become opaque that such a decision was ever made.

In STS, this dynamic is often analysed with the notion of 'scripts', a concept which captures how artefacts come with inscribed scenarios for their use (Akrich, 1992, 1995). Such scenarios can be very normative and may enable and constrain actions of the users of a technology. Hence, 'age scripts' (Neven, 2010; Peine and Neven, 2011) are scenarios for use which guide an older user in more or less subtle ways to certain intended actions, often as a result of a deliberate act on the part of the designer based on ideas of what is or is not appropriate, safe, interesting or wise for an older user to do. Age scholars working with STS concepts have used the script idea to grasp how fitness trackers contribute to the 'responsibilisation' of older people for their own health (Urban, 2017), how exercise games prescribe what is deemed a useful exercise and what not (Wanka and Gallistl, 2018) or, more generally, how assistive technologies reinforce trends towards the subjectivation of age-related risks and vulnerabilities in the neoliberal economy (Endter, 2016). Neven (2015) provides an example of a telecare system which was designed with a limited interface that did not allow older users to turn the system off. The older users could only passively accept being monitored which meant giving up private information (e.g. about their nightly behaviour) and access to certain places in the home. The only other option was to have the system removed entirely. However, this latter choice could well reopen negotiations with their children and other carers about the question of whether it was still safe for them to live at home, so there was a severe potential penalty for removing the monitoring system. Technologies for older people may thus come with scripts which 
severely constrain or change the lives of older people with few opportunities for them to resist or creatively circumvent such scripts.

Some age scripts thus force older people to do certain things or accept that certain things are done to them. Other scripts are more open to being 'read' in certain ways by the older user. Aceros et al. (2015), for instance, demonstrate more subtle effects of telecare systems. They showed how these systems come with prescriptions of users as home-bound and of home environments as risky. The prescriptions were material manifestations of the widespread 'ageing in place' discourse. Designers and telecare providers translated this discourse into the idea that it is the primary aim of telecare devices to create secure home spaces, and they configured the devices and the accompanying installation and use instructions accordingly. Aceros et al. (2015) describe the case of Antonio, a user of a new alarm pendant who did not think of himself as being at risk or of his home as being risky. He initially used the alarm pendant only in situations that he found risky, notably in the shower. The telecare workers noted this as an unruly pendant (see above) because for them a proper pendant would configure a user to carry it all the time. To restore a proper pendant, the workers pointed out to Antonio the many risks that he was facing at home, and why it was thus important to wear the pendant all the time. 'The volunteer's remarks contributed to Antonio's idea, whether or not he was conscious of it, of being a person who was always at risk' (Aceros et al., 2015: 105). Antonio gradually became a subject who was more in line with the role identities the designers of the system had in stock for him: 'Docile users begin considering themselves as elderly people who do indeed need care' (Aceros et al., 2015: 105).

This example demonstrates how a version of ageing - old people are constantly at risk and need to be able to call in an emergency at all times - entered Antonio's home with the alarm pendant. Antonio as a person 'not constantly at risk' could not meaningfully relate to the designers' and care professionals' version of the alarm pendant. Instead, the new arrangement tried to configure him as a person at risk, and when appropriating the new technology, Antonio had to relate to this new identity. Of course, Antonio found ways to evade this rather narrow prescription and to convince the alarm pendant to meet him halfway (in the end, Antonio did use the pendant only at certain places). The point is, however, that the new artefact forced him to grapple with the prescriptions the designers and installers had in stock for him, and enter into negotiations with them (and indeed, evasive actions may not always be possible or be very limited, shown by the example from Neven, 2015). Also, the specific alarm pendant had no option for Antonio to engage with the broader and more malleable ageing-in-place discourse that the pendant was meant to represent. Much of this discourse was black-boxed in the alarm pendant, and thus gave way to much narrower ideas of risks and safety as pertinent dimensions of ageing-in-place.

It is not our intention to invite ageing and technology scholars to use the script concept per se. Instead, the CAT-model emphasises a more general point for studying ageing and technology: technological artefacts come with inscribed ideas about their users and use. They enable and constrain how older people can relate to them, although older people are, of course, not powerless. Technological artefacts thus transfer the results of co-constitution that takes place in design worlds into the life- 
worlds of older people, and they do so in often implicit, unintentional, obdurate and unruly ways. Hence, these artefacts deserve our attention, not as neutral and malleable objects to be vested with meaning, ${ }^{9}$ but as actors that perform meaning by the specific way in which they are designed, marketed and supplied. It is through the specific ways of inscribing and black-boxing that articulations of ageing from design worlds come to matter in the life-worlds of older people. The CAT-model highlights that relationships of older people with technologies do not start from scratch, but they have to negotiate, although across significant distance, the ideas of designers, company boardrooms, policy makers and others that come, often implicitly in distorted ways, with technological artefacts.

\section{Conclusion}

Articulations of ageing-technology relations made in either a design or a life-world are not isolated but contribute to longer-term definitions of both ageing and technology. In grasping CAT, we need to attend to such longer-term effects that become visible if we follow multiple forms and emergences of ageing-technology relations across various sites. ${ }^{10}$ Articulations of ageing-technology relations made in one of these worlds are not isolated. They are mobile, carry with them realities and normativities, and thus can unfold effects far remote from their origins (Mol, 1999: 75). For instance, versions of ageing made by designers are not innocent because they enter the life-worlds of older people together with the technical objects that they helped create; and vice versa, unexpected appropriations and uses of technology should not be seen as just local particularities. Over time, they can sum up to changes in what the technology in question is and does (Pollock et al., 2007), and, as we would like to add, also contribute to what old people are and should be doing. In this sense, our perspective is equally sensitive to processes of local emergence and longer-term structural developments through which such processes may or may not stabilise.

In this article, we outlined the basic structure, characteristics and advantages of a new model for studying ageing and technology, the CAT-model. With this model we hope to foster a deeper, more symmetrical, analytically equal, cyclical understanding of the way older people and technology co-constitute each other. Technology produces new users (or not), new technological fixes are produced that enable and constrain, but also replace old ideas about ageing and fix new ones in place. New ideas about ageing are produced by older people and others responding to new technologies or other outside influences. This in turn influences technology development and so the cycle continues, with many other factors and actors playing a role. No site or arena on the cycle is a priori more important than another one; and there is a transferral of objects and ideas between these arenas. Technology may be influenced by (perceptions of) ageing and in turn change what it means to age which can in turn influence perceptions of ageing. Although the cycle can stop at any point - we stress, however, that innovation processes regularly do lead to technologies that are used in everyday life - it can also keep cycling so that technologies are modified and older people learn about and adapt to new technologies. ${ }^{11}$ 
The most important point of the cyclical structure of the CAT-model is that we do away with models which presuppose an (implicit) technology-push perspective and in which common notions like 'acceptance', 'implementation' or 'impact' are the stable endpoint which can and must be created or produced by a technological 'intervention' (and in which an older user is dubbed deviant if she or he does not comply). The acceptance, impact or stable use of technology is not presupposed in the CAT-model. Indeed, the objective of the CAT-model is not to facilitate acceptance, impact or use, but to study whether and how technologies and their use do or do not come about. The best - and indeed only - way of understanding acceptance, impact or use of technology in the lives of older people is to start from a model that does not presuppose it. This is a key point where CAT deviates from interventionist models of ageing and technology whose underlying implicit theories have mostly been driven by practical concerns (Peine and Neven, 2019). CAT provides a basis for scholars and practitioners to systematically study and acknowledge the multiple forms of ageing-technology relations, and the versions of ageing and technology they enact, at various sites and across time. For us, this seems to be a crucial preliminary to theorise about ageing in ways that acknowledge technology as an inherent and constitutive factor of it.

While, to paraphrase Latour (1987), we believe that the fate of our CAT-model is ultimately in the hands of its users, we would like to flag two practical implications of our model that we deem particularly relevant. First, the CAT-model highlights that the life-worlds of older people are no stable targets for interventions. The examples we discuss above show instead that when technology comes to matter in the lives of older people, they do so by, for example, co-constituting new values (i.e. what is privacy), practices (i.e. what is proper use?) and subjectivities (am I healthy or at risk?) - all of which are dynamically negotiated over time. The dynamic and diverse nature of the relation between older people and technologies has repercussions, for instance, for the skills of social and health-care professionals. These professionals are increasingly confronted with technologies in their everyday practice. It is important for such professionals to understand that technology may enable but also constrain older people, often in unexpected ways. It is also important for them to understand that technology contains versions of ageing which may be considered stigmatising by older people. The CAT-model provides a basis for teaching social and health-care professionals how to make critical analyses of the (ethical) effects of technologies on the lives of (vulnerable) older people.

Secondly, there is a more specific challenge for designers. That is, the CAT-model questions the widespread concern with user needs or requirements in gerontechnology. Indeed, our model highlights that needs and requirements are not stable or fixed 'entities', but that they will change or, more precisely, come into existence only together with the technologies that are meant to meet them in the first place. To conclude then, our model invites designers, innovation policy makers, (social) care professionals, health professionals and others to anticipate on the multiple and dynamic forms that the co-constitution of ageing and technology can take.

This article builds on a line of research that both authors have contributed to substantially over the last years. Both authors contributed during all parts of the conception and design of the model. AP had the main responsibility for drafting the 
first version of the manuscript and both authors contributed significantly to the re-writing that led to the submitted version.

Conflict of interest. The authors declare no conflicts of interest.

Ethical standards. No ethical approval was required for this article.

\section{Notes}

1 Our use of co-constitution has roots in both social gerontology and STS. In the former, the idea that human ageing is socially constituted goes back to the work of Baars and Dannefer, who have developed it to complement biological notions of human ageing and also as an extension to social constructionism in a strict sense (Baars, 1991; Dannefer, 1999; Dannefer and Daub, 2009). In STS, it is widely associated with the work of Karen Barad, who uses it to remind us that we should not take the distinction between humans and non-humans for granted; rather, this very distinction itself, like every ontology, is constituted in specific intra-actions. Humans and non-humans co-constitute each other (Barad, 2007).

2 We have chosen to use the term Age Studies here, rather than possible alternatives like social or critical gerontology, or ageing studies, because it is open to a broad variety of disciplinary backgrounds, including the humanities, the social sciences and the sciences (Katz, 2014). While we are aware of the ongoing debates around the appropriate terminology regarding age versus ageing, or age studies versus any of the gerontologies (Gullette, 2018; Higgs and Gilleard, 2020), our choice for Age Studies is purely pragmatic. Indeed, exploring the value and risks of different terminologies in relation to technology would require a paper in its own right.

3 The term 'multiple' has a specific meaning in STS and goes back to the work of Dutch STS scholar Annemarie Mol (1999, 2002): techno-scientific objects, like privacy or an alarm pendant, do not exist independent of the socio-material networks that perform their existence. Hence, objects are not just perceived differently by different actors, but they are different objects in different realities. Hence, an object is always multiple, but not necessarily plural. 'It is not as if there were separate entities each standing apart in a homogeneous field' (Mol, 1999: 85). Rather, the notion of multiplicity requires us to trace carefully how objects are enacted differently, and how such enactments can overlap, collaborate and imply each other. Our wording is important here: when we talk about multiple versions of a technology, we mean that 'an object is more than one but less than many' (Law, 2017: 43). The challenge here is to let go of simplistic ideas of a technology as either stable or fully malleable and engage with the messy middle ground where a technical object has multiple identities across social worlds, which are connected loosely by that object (Bijker, 1995; Mol, 1999: 75).

4 The use of arrows in any model requires explanation. To be clear, the arrows are there to indicate a clearly dominant, but not necessary, direction of transferal between the arenas. They are not filled with meaning in the sense that they are not to be seen as arenas themselves, though obviously the transferral between arenas is an object for research. What is actually transferred can differ, it can be (a combination of) ideas, images, policies, designs, material objects, the bits and bytes of software, etc. The question whether there is transferal and what is actually transferred is an empirical question, which is what the arrows and arenas aim to highlight.

5 CAT is a multi-sited phenomenon that cuts across multiple, overlapping worlds. When we talk about design worlds and life-worlds, this is an analytical simplification: what we have broadly termed life-worlds includes the whole range of sites traditionally studied by ageing scholars: homes and communities, care homes, rehabilitation centres, hospitals, social media, advertisements and others. But a co-constitution perspective requires age studies to include a completely different set of locations as well, which we have indicated with the term design worlds. These may include design laboratories, gerontechnological research, innovation policy, prototype implementations and many more.

6 Indeed, with STS in mind, we would like to encourage students of ageing and technology relations to be careful about making assumptions about what are human and what are technological attributes. STS calls for symmetrical analysis of human and non-human actors as it does not want to make assumptions about, for example, agency being a human attribute, but instead analyses how agency is distributed in networks of human and non-human actors. There has been recent attention to such a post-humanist turn in Age Studies itself (Höppner and Urban, 2018; Andrews and Duff, 2019). It seems, though, that this turn is 
limited to including objects in the analysis of live worlds, while it is less clear in how far it embraces the notion that objects are equally unstable as humans. This latter aspect is crucial to the CAT perspective and its relevance will become clear as we continue our discussion of the other arenas in our network.

7 This has been recognised by some ageing scholars. For instance, Twigg (2012) showed how fashion designers relied on the up-beat and empowered imagery of older bodies associated with ideals of positive ageing and consumerism (Katz and Marshall, 2003) when they decided about the styles of clothes suitable for the grey market. Our point is that this link between images of ageing and design has not been a central one on the ageing and technology agenda, so far.

8 In STS parlance, Peine and Moors (2015) have traced the various anticipatory assemblages populated by robots, older people and many others, and how these assemblages changed and stabilised during the design process. Only eventually, those assemblages prevailed that enacted passive and frail older people together with robots that could 'help' them, which gave rise to specific distributions of agencies among the robots and prospective older users. But these specifications were socially and materially contingent, i.e. passivity and frailty emerged as contingent attributes in a network where myriad of other attributes - most of which, again, had nothing to do with age or ageing - had to be fixed as well.

9 Which is the way in which more recent debates around new materialism or posthumanism in Age Studies seem to conceptualise the relevance of material objects (see Chapman, 2006; Höppner and Urban, 2018; Andrews and Duff, 2019).

10 This claim links to the STS literature that has been critical to the narrative bias in STS towards uniqueness and idiosyncrasy rather than longer-term processes and social scales (Jorgensen and Sorensen, 1999; Pollock et al., 2007; Hess et al. 2017). This literature has originated from studying software enterprise solutions like Enterprise Resource Planning (ERP) software (Pollock and Williams 2008, 2010; Williams and Pollock, 2012), but has also gained significant traction in the study of health technologies (e.g. Faulkner, 2009; Hyysalo, 2010; Peine and Moors, 2015).

11 There should be no presumption of a helix. 'Progress' towards a 'better' technology is not a given outcome, though there is also no reason to presuppose that improvements of technologies are impossible (indeed what counts as progress or better is obviously contextual and thus differs for the multitude of actors involved). Whether the technology fits or does not fit with the life-world of an older person is an empirical question. Moreover, the CAT-model should not be seen as a closed loop; there can be feed-in and feed-out in any arena. For example, the images of ageing do not necessarily have to stem from the life-world of older people. They can also be based on broad (ageist) assumptions of ageing that are in no way related to the empirical reality of the lives of older people.

\section{References}

Aceros JC, Pols J and Domènech M (2015) Where is grandma? Home telecare, good aging and the domestication of later life. Technological Forecasting and Social Change 93, 102-111.

Akrich M (1992) The de-scription of technical objects. In Bijker WE and Law J (eds), Shaping Technology/ Building Society - Studies in Sociotechnical Change. Cambridge, MA: MIT Press, pp. 205-224.

Akrich M (1995) User representations: practices, methods and sociology. In Rip A, Misa TJ and Schot J (eds), Managing Technology in Society: The Approach of Constructive Technology Assessment. London: Pinter Publishers, pp. 167-184.

Akrich M and Latour B (1992) A summary of a convenient vocabulary for the semiotics of human and nonhuman assemblies. In Bijker WE and Law J (eds), Shaping Technology/Building Society-Studies in Sociotechnical Change. Cambridge, MA: MIT Press, pp. 259-264.

Andrews G and Duff C (2019) Understanding the vital emergence and expression of aging: how matter comes to matter in gerontology's posthumanist turn. Journal of Aging Studies 49, 46-55.

Baars J (1991) The challenge of critical gerontology: the problem of social constitution. Journal of Aging Studies 5, 219-243.

Barad K (2007) Meeting the Universe Halfway: Quantum Physics and the Entanglement of Matter and Meaning. Durham, NC: Duke University Press.

Berridge C (2016) Breathing room in monitored space: the impact of passive monitoring technology on privacy in independent living. The Gerontologist 56, 807-816. 
Berridge C (2017) Active subjects of passive monitoring: responses to a passive monitoring system in lowincome independent living. Ageing \& Society 37, 537-560.

Bijker WE (1995) Of Bicycles, Baekelite and Bulbs: Towards a Theory of Sociotechnical Change. Cambridge, MA: MIT Press.

Bucciarelli LL (1988) An ethnographic perspective on engineering desgin. Design Studies 9, 159-168.

Buse C, Nettleton S, Martin D and Twigg J (2017) Imagined bodies: architects and their constructions of later life. Ageing \& Society 37, 1435-1457.

Chapman SA (2006) A 'new materialist' lens on aging well: special things in later life. Journal of Aging Studies 20, 207-216.

Cozza M, De Angeli A and Tonolli L (2017) Ubiquitous technologies for older people. Personal and Ubiquitous Computing 21, 607-619.

Dannefer D (1999) Neoteny, naturalization and other constituents of human development. In Ryff CD and Marshall VW (eds), The Self and Society in Aging Processes. Springer Publishing Company: New York, pp. 68-92.

Dannefer D and Daub A (2009) Extending the interrogation: life span, life course, and the constitution of human aging. Advances in Life Course Research 14, 15-27.

Endter C (2016) Skripting age - the negotiation of age and aging in ambient assisted living. In DomínguezRué E and Nierling L (eds), Ageing and Technology-Perspectives from the Social Sciences. Bielefeld, Germany: transcript, pp. 121-140.

Faulkner A (2009) Medical Technology into Healthcare and Society: A Sociology of Devices, Innovation and Governance. Basingstoke, UK: Palgrave Macmillan.

Featherstone M and Wernick A (eds) (1995) Images of Aging-Cultural Representations of Later Life. London: Routledge.

Felt U, Fouché R, Miller C and Smith-Doerr L (eds) (2017) The Handbook of Science and Technology Studies. Cambridge, MA: MIT Press.

Fernández-Ardèvol M, Rosales A, Loos E, Peine A, Beneito-Montagut R, Blanche D, Fischer B, Katz S and Östlund B (2019) Methodological strategies to understand smartphone practices for social connectedness in later life. In Zhou J and Salvendy G (eds), Lecture Notes in Computer Science: Human Aspects of IT for the Aged Population. Social Media, Games and Assistive Environments. Cham, Switzerland: Springer International Publishing, pp. 46-64.

Giaccardi E, Kuijer L and Neven L. (2016) Design for resourceful ageing: intervening in the ethics of gerontechnology. In Lloyd P and Bohemia E (eds), Proceedings of drs2016: Design + research + society future-focused thinking, vol. 9. London: Design Research Society, pp. 3553-3566.

Gibson G, Dickinson C, Brittain K and Robinson L (2019) Personalisation, customisation and bricolage: how people with dementia and their families make assistive technology work for them. Ageing \& Society 39, 2502-2519.

Gullette MM (2018) Against 'aging' - how to talk about growing older. Theory, Culture \& Society 35, 251270.

Hedman A, Kottorp A and Nygård L (2018) Patterns of everyday technology use and activity involvement in mild cognitive impairment: a five-year follow-up study. Aging and Mental Health 22, 603-610.

Hess D, Amir S, Frickel S, Kleinman DL, Moore K and Williams LDA (2017) Structural inequality and the politics of science and technology. In Felt U, Fouché R, Miller C and Smith-Doerr L (eds), The Handbook of Science and Technology Studies, 4th Edn. Cambridge, MA: MIT Press, pp. 319-347.

Higgs P and Gilleard C (2020) The ideology of ageism versus the social imaginary of the fourth age: two differing approaches to the negative contexts of old age. Ageing \& Society 40, 1617-1630.

Higgs P, Hyde M, Gilleard C, Victor CR, Wiggins RD and Jones IR (2009) From passive to active consumers? Later life consumption in the UK from 1968-2005. Sociological Review 57, 102-124.

Höppner G and Urban M (2018) Where and how do aging processes take place in everyday life? Answers from a new materialist perspective. Frontiers in Sociology 3, 7.

Hyysalo S (2009) Learning for learning economy and social learning. Research Policy 38, 726-735.

Hyysalo S (2010) Health Technology Development and Use: From Practice-bound Imagination to Evolving Impacts. London: Routledge.

Jorgensen U and Sorensen OH (1999) Arenas of development - a space populated by actor-worlds, artefacts and surprises. Technology Analysis \& Strategic Management 11, 409-429. 
Joyce K and Mamo L (2006) Graying the cyborg: new directions in feminist analyses of aging, science, and technology. In Calasanti T and Slevin K (eds), Age Matters: Realigning Feminist Thinking. New York, NY: Routledge, pp. 99-121.

Joyce K, Peine A, Neven L and Kohlbacher F (2017) Aging: the socio-material constitution of later life. In Felt U, Fouché R, Miller C and Smith-Doerr L (eds), The Handbook of Science and Technology Studies, 4th Edn. Cambridge, MA: MIT Press, pp. 915-942.

Katz S (2001) Growing older without aging? Positive aging, anti-ageism, and anti-aging. Generations 25, 27-32.

Katz S (2014) What is age studies. Age, Culture, Humanities 1, 17-23.

Katz S and Marshall B (2003) New sex for old: lifestyle, consumerism, and the ethics of aging well. Journal of Aging Studies 17, 3-16.

Katz S and Marshall BL (2018) Tracked and fit: Fitbits, brain games, and the quantified aging body. Journal of Aging Studies 45, 63-68.

Kudina O and Verbeek P-P (2019) Ethics from within: Google Glass, the Collingridge dilemma, and the mediated value of privacy. Science, Technology, \& Human Values 44, 291-314.

Kwon S (ed.) (2017) Gerontechnology: Research, Practice, and Principles in the Field of Technology and Aging. New York, NY: Springer.

Lassen AJ, Bønnelycke J and Otto L (2015) Innovating for 'active ageing' in a public-private innovation partnership: creating doable problems and alignment. Technological Forecasting and Social Change 93, $10-18$.

Latour B (1987) Science in Action: How to Follow Scientists and Engineers Through Society. Cambridge, MA: Harvard University Press.

Latour B (1993) We Have Never Been Modern. Cambridge, MA: Harvard University Press.

Latour B and Woolgar S (1979) Laboratory Life: The Social Construction of Scientific Facts. Beverly Hills, CA: Sage.

Law J (2017) STS as method. In Felt U, Fouché R, Miller C and Smith-Doerr L (eds), The Handbook of Science and Technology Studies, 4th Edn. Cambridge, MA: MIT Press, pp. 31-57.

Loe M (2010) Doing it my way: old women, technology and wellbeing. Sociology of Health \& Illness 32, 319-334.

López Gómez D (2015) Little arrangements that matter. Rethinking autonomy-enabling innovations for later life. Technological Forecasting and Social Change 93, 91-101.

Mackay H, Carne C, Beynon-Davies P and Tudhope D (2000) Reconfiguring the user: using rapid application development. Social Studies of Science 30, 737-757.

Marshall BL (2018) Happily ever after? 'Successful ageing' and the heterosexual imaginary. European Journal of Cultural Studies 21, 363-381.

Marshall BL and Katz S (2016) How old am I? Digital culture and quantified ageing. Digital Culture \& Society 2, 145-152.

McCreadie C and Tinker A (2005) The acceptability of assistive technology to older people. Ageing \& Society 25, 91-110.

Meagher M (2015) Art, ageing and the body. In Twigg J and Martin W (eds), Routledge Handbook of Cultural Gerontology. London: Routledge, pp. 85-92.

Mol A (1999) Ontological politics. A word and some questions. The Sociological Review 47, 74-89.

Mol A (2002) The Body Multiple: Ontology in Medical Practice. Durham, NC: Duke University Press.

Mort M, Roberts C, Pols J, Domenech M and Moser I (2015) Ethical implications of home telecare for older people: a framework derived from a multisited participative study. Health Expectations 18, 438449.

Neven L (2010) 'But obviously not for me': robots, laboratories and the defiant identity of elder test user. Sociology of Health and Illness 32, 335-347.

Neven L (2011) Representations of the Old and Ageing in the Design of the New and Emerging: Assessing the Design of Ambient Intelligence Technologies for Older People. Enschede, The Netherlands: University of Twente.

Neven L (2015) By any means? Questioning the link between gerontechnological innovation and older people's wish to live at home. Technological Forecasting and Social Change 93, 32-43.

Neven L and Peine A (2017) From triple win to triple sin: how a problematic future discourse is shaping the way people age with technology. Societies 7, 26-37. 
Östlund B (2005) Design paradigms and misunderstood technology: the case of older users. In Jaeger B (ed.), Young Technologies in Old Hands - An International View on Senior Citizen's Utilization of ICT. Copenhagen: DJOF Publishing, pp. 25-39.

Oudshoorn N and Pinch T (eds) (2003a) How Users Matter: The Co-construction of Users and Technologies. Cambridge, MA: MIT Press.

Oudshoorn N and Pinch T (2003b) Introduction: How users and non-users matter. In Oudshoorn N and Pinch T (eds), How Users Matter: The Co-construction of Users and Technologies. Cambridge, MA: MIT Press, pp. 1-25.

Oudshoorn N, Rommes E and Stienstra M (2004) Configuring the user as everybody: gender and design cultures in information and communication technologies. Science, Technology and Human Values 29, $30-63$.

Peek ST, Luijkx KG, Rijnaard MD, Nieboer ME, van der Voort CS, Aarts S, van Hoof J, Vrijhoef HJ and Wouters EJ (2016) Older adults' reasons for using technology while aging in place. Gerontology 62, 226-237.

Peine A and Herrmann AM (2012) The sources of use knowledge: towards integrating the dynamics of technology use and design in the articulation of societal challenges. Technological Forecasting and Social Change 79, 1495-1512.

Peine A and Moors EHM (2015) Valuing health technology - habilitating and prosthetic strategies in personal health systems. Technological Forecasting and Social Change 93, 68-81.

Peine A and Neven L (2011) Social-structural lag revisited. Gerontechnology 10, 129-139.

Peine A and Neven L (2019) From intervention to co-constitution: new directions in theorizing about aging and technology. The Gerontologist 59, 15-21.

Peine A, Rollwagen I and Neven L (2014) The rise of the 'innosumer' - rethinking older technology users. Technological Forecasting and Social Change 82, 199-214.

Peine A, Faulkner A, Jæger B and Moors E (2015) Science, technology and the 'grand challenge' of ageing - understanding the socio-material constitution of later life. Technological Forecasting and Social Change 93, 1-9.

Peine A, van Cooten V and Neven L (2017) Rejuvenating design: bikes, batteries, and older adopters in the diffusion of e-bikes. Science, Technology \& Human Values 42, 429-459.

Pollock N and Williams R (2008) Software and Organizations - The Biography of the Enterprise-wide System or How SAP Conquered the World. Abingdon, UK: Routledge.

Pollock N and Williams R (2010) E-infrastructures: how do we know and understand them? Strategic ethnography and the biography of artefacts. Computer Supported Cooperative Work 19, 521-556.

Pollock N, Williams R and D'Adderio L (2007) Global software and its provenance: generification work in the production of organizational software packages. Social Studies of Science 37, 254-280.

Rosales A and Fernández-Ardèvol M (2016) Beyond WhatsApp: older people and smartphones. Romanian Journal of Communication and Public Relations 18, $27-47$.

Schulz R, Wahl HW, Matthews JT, De Vito Dabbs A, Beach SR and Czaja SJ (2015) Advancing the aging and technology agenda in gerontology. The Gerontologist 55, 724-734.

Sismondo S (2010) An Introduction to Science and Technology Studies. Chichester, UK: Wiley-Blackwell.

Sixsmith A (2009) Understanding the older user of ambient technologies. In Jacko JA (ed.), HumanComputer Interaction. Berlin: Springer, pp. 511-519.

Sixsmith A (2013) Technology and the challenge of aging. In Sixsmith A and Gutman G (eds), Technologies for Active Aging. New York, NY: Springer, pp. 7-25.

Stewart J and Williams R (2005) The wrong trousers? Beyond the design fallacy: social learning and the user. In Howcroft D (ed.), Handbook of Critical Information Systems Research. Cheltenham, UK: Edward Elgar, pp. 195-221.

Suopajärvi T (2015) Past experiences, current practices and future design. Technological Forecasting and Social Change 93, 112-123.

ten Bruggencate T, Luijkx KG and Sturm J (2019) When your world gets smaller: how older people try to meet their social needs, including the role of social technology. Ageing \& Society 39, 1826-1852.

Twigg J (2012) Adjusting the cut: fashion, the body and age on the UK high street. Ageing \& Society 32, $1030-1054$.

Twigg J (2018) Fashion, the media and age: how women's magazines use fashion to negotiate age identities. European Journal of Cultural Studies 21, 334-348. 
Urban M (2017) 'This really takes it out of you!' The senses and emotions in digital health practices of the elderly. Digital Health 3, 1-16.

van Bronswijk JEMH, Bouma H and Fozard JL (2002) Technology for quality of life: an enriched taxonomy. Gerontechnology 2, 169-172.

Van Hees S, Horstman K, Jansen M and Ruwaard D (2018) Meanings of 'lifecycle robust neighbourhoods': constructing versus attaching to places. Ageing \& Society 38, 1148-1173.

Vines J, Pritchard G, Wright P, Olivier P and Brittain K (2015) An age-old problem: examining the discourses of ageing in HCI and strategies for future research. ACM Transactions on Computer-Human Interaction 22, 1-27.

Wanka A and Gallistl V (2018) Doing age in a digitized world - a material praxeology of aging with technology. Frontiers in Sociology 3, Article 6.

Williams R and Pollock N (2012) Moving beyond the single site implementation study: how (and why) we should study the biography of packaged enterprise solutions. Information Systems Research 23, 1-22.

Woolgar S (1991) Configuring the user: the case of usability trials. In Law J (ed.), A Sociology of Monsters: Essays on Power, Technology and Domination. London: Routledge, pp. 57-99.

Cite this article: Peine A, Neven L (2021). The co-constitution of ageing and technology - a model and agenda. Ageing \& Society 41, 2845-2866. https://doi.org/10.1017/S0144686X20000641 